\title{
Take Out Your Cell Phones - Class is Starting
}

\author{
Jason Bazylak, Susan McCahan, Peter Elliot Weiss, and Phil Anderson \\ University of Toronto \\ jbazylak@mie.utoronto.ca mccahan@mie.utoronto.ca weissp@ecf.utoronto.ca p.anderson@utoronto.ca
}

\begin{abstract}
Traditionally, cell phones have been considered disruptive to classroom learning. Two years ago, a survey of students in a large first year design course indicated that $88 \%$ of students possessed cell phones in the classroom. Instead of trying to enforce a cell phone ban, and fight a losing battle, we decided to use the cell phones to our pedagogical advantage. Previously, student interaction in the classroom was a challenge, due to a large class of students in a single lecture theater. A primary issue was the inability of all except a few students with booming voices to ask questions. Informed primarily by a student design team (from the very course being discussed), we implemented a simple and inexpensive system that allowed students to use their cell phones in the classroom to send questions via Short Message Service (SMS), commonly referred to as "text messages", to the instructor at the front of the classroom This system has been piloted through its first year of full implementation. Quantitative data on the usage of the system, student and instructor impressions of the system, and future work will be discussed.
\end{abstract}

Keywords: text messaging, SMS, active learning, large class, educational technology

\section{INTRODUCTION}

In a large first-year engineering course of approximately 1000 student in a single lecture theatre, classroom management and student - instructor interactivity have always been challenges (see fig. 1).

Previously, cell phones have been considered disruptive to classroom learning and their use in the classroom was strictly banned. This ban was enforced through the highly inefficient method of having members of the teaching team patrol the lecture theatre. The problem, besides a poor use of teaching team time, is that it was difficult to decisively catch students in the act. Even if a student was caught, the choice of sanctions was either immediate ejection of the student from the classroom for a relatively common offense or to attempt to track repeat offenders. The first option was more disruptive to the classroom then the behavior it was intended to curb. The second option was not a good use of teaching team resources.

Improvements to student - instructor interaction have already been made through large classroom active learning techniques such as Think-Pair-Share and inclassroom conceptual design challenges. These strategies have had good success, but they do not reach all students. Additionally student feedback is collected in lectures through an electronic classroom response system, Iclickers. The problem with the Iclicker system is that it only collects mass feedback and is only instructor initiated. It is effective for an instructor to clarify general class understanding of topics, but it is useless if a student wants to ask a specific question. Students wanting to ask a specific question can attempt the traditional method of raising their hand. This required first that the student to be confident enough not to be intimidate by the large forum, second for the instructor to notice the single hand in an sea of faces, third for the student to project their voice in sufficient volume to be heard from a great distance, and finally for the instructor to be able to hear and understand and then answer the question. This was time consuming, particularly when there was a back and forth dialogue between the instructor and student trying to understand the question. Therefore though strides had been made in student - instructor interaction, there was still room for improvement.

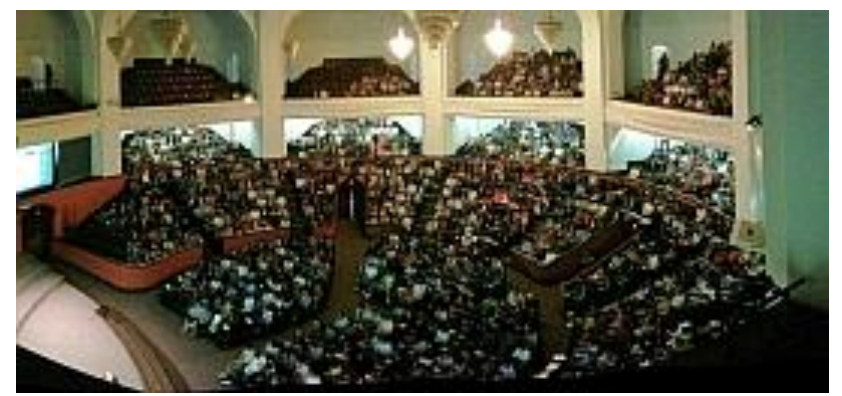

Figure 1: Approximately two-thirds of students enrolled in the course

In 2010 the issue of answering questions in the classroom was posed as a design problem to a student design team enrolled in the course as their term-long design project. Their solution of using Short Message 
Service (SMS) as a medium for asking questions is given in an unpublished final design specification[1]. The solution not only addressed the problem posed to them, but with typical engineering efficiency also solved the problem of how to deal with the cell phone ban: allow cell phones. One of the first uses of student texting in this classroom, during the initial three month pilot, was a creativity exercise where the instructor stood atop a table in the middle of the stage, cell phone in hand. He instructed the students to text in as many ways to get him off the table as possible. Five minutes and 300 text messages later an unintended function of the design, to create a level of student engagement rarely seen in a large classroom, was discovered.

The use of SMS in the classroom has been explored before. Yengina et al conducted a literature review of uses of SMS in education across the globe. One main use of SMS for education was identified as a question and answer feedback system [2]. Yengina also gives a fairly high estimated economic cost for SMS systems by educational institutions; however as with any technology rapidly moving towards ubiquity, these costs are dropping rapidly.

Markett et al also present an extensive literature review for the use of SMS in education as foundational work to their PLS TXT UR Thoughts project [3]. This project included use of SMS via a software system custom designed to encourage student interactivity in the classroom. Their project found moderate success within a small classroom setting; however they do speculate that in-classroom SMS would find more success in a large classroom setting. Encouraged by these findings the teaching team decided to move forward with a highly simplified pilot in order to minimize implementation and maintenance costs.

\section{METHODOLOGY}

In spring 2011, for a three month period, a SMS question answer system was implemented. A teaching assistant (TA), armed with a borrowed cell phone, was present on stage with the instructor. Students were encouraged to use standard SMS to send questions to the instructor through the TA. The TA summarized and presented the questions to the instructor at appropriate times via a handheld whiteboard. Other approaches were considered, but this method had the lowest technology threshold for both the students and instructors and required minimal financial investment.

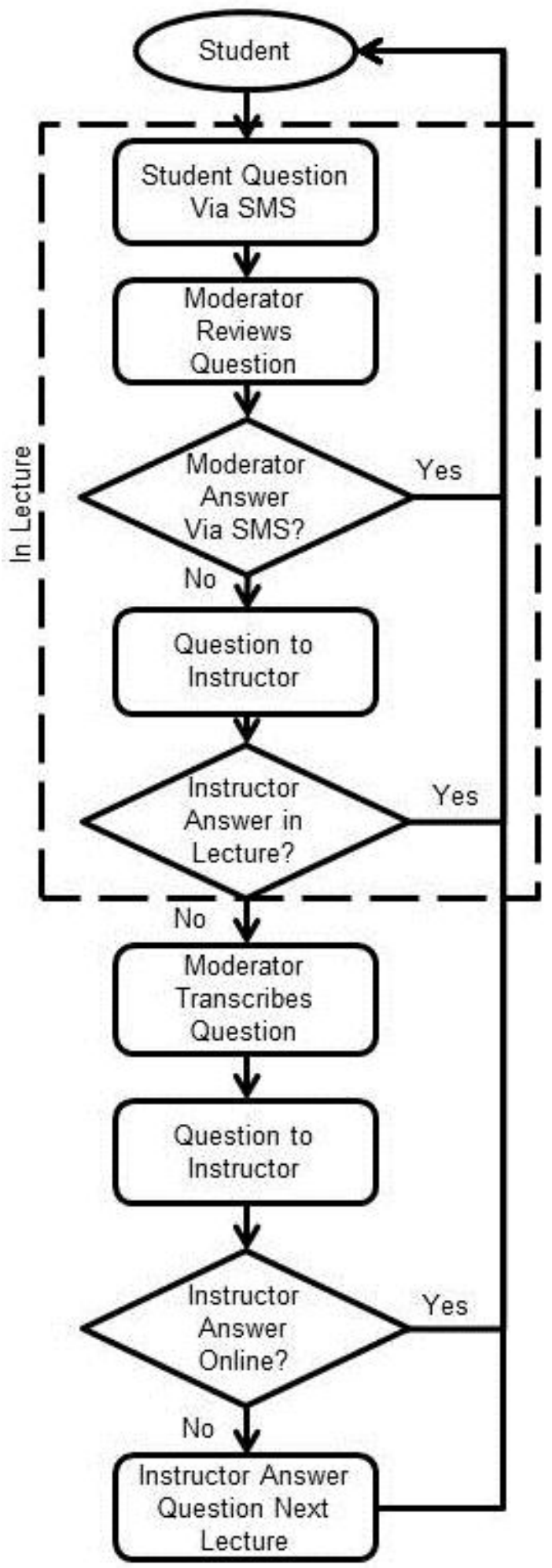

Figure 2: Closed loop student feedback for SMS questions

For eight months between the Fall 2011 and the Spring 2012, the same SMS system was implemented, except that a member of the course staff member took over as 
question moderator. Additionally the course purchased a cell phone to avoid borrowing one. Questions texted in during lecture were handled in one of three ways. Each method was a closed loop to ensure student feedback and trust of the system (see fig.2).

If the question was strictly factual and of little discussion value, such as "What is the due date of the assignment?", then the moderator would directly respond to the student question via SMS. Otherwise the moderator would present the question to the instructor at an appropriate time. If there was insufficient time to address all the questions in lecture then the moderator would transcribe the questions and supply them to the instructor via email after class. The instructor would then either answer the question online or at the start of next lecture.

The student design team recommended the use of a laptop with free messaging software, Yahoo's AIM messenger service, for the monitoring the text messages. Other services such as Twitter and a custom software package designed and implemented by a senior undergraduate design team were also considered. These were all dismissed because they required students to register for an account beforehand, and because a wireless service was unavailable in this venue. Instead the decision was to go with an older standard such as SMS as it has the lowest technology threshold and had the best chance of being ubiquitous amongst the students. In this way nearly any student could ask a question on a moment's notice simply by typing in the course phone number. This did however create additional work for the teaching team in archiving these SMS messages. Unlike the more complex systems that give access to SMS messages in an editable form the simple system required manual transcribing of my data.this was a tradeoff made in order to make the system available to as many students as possible.

The resources to implement this system were kept to a minimum. A cell phone with an easy to read texting interface and full keyboard was secured with zero costs, even without commitment to a long term cell phone contract. A cell phone service plan with a sufficient text message limit to handle the traffic is under $\$ 20$ per month. The only significant resource course cost was the time of the teaching team staff member. This required the time to attend every lecture over two terms, and an equal amount of time outside of lecture transcribing text messages, sending email requests, and posting solutions. This totaled approximately 140 hours over the course of eight months.

\section{RESULTS AND DISCUSSION}

The effectiveness of this system was measured through three primary sources of data. First usage of the system was quantitatively monitored using the text message log on the course cell phone to determine if the system was being used by the students. Second instructors utilizing the system were asked for anecdotal evidence on the effect the system had on their lectures. Finally in the yearend online survey students were asked the question, "Texting in of questions during class was useful to me."

\subsection{Usage Data}

The number of unique cell phone numbers texting in questions was tracked over the eight month period with the results seen in fig. 3 .

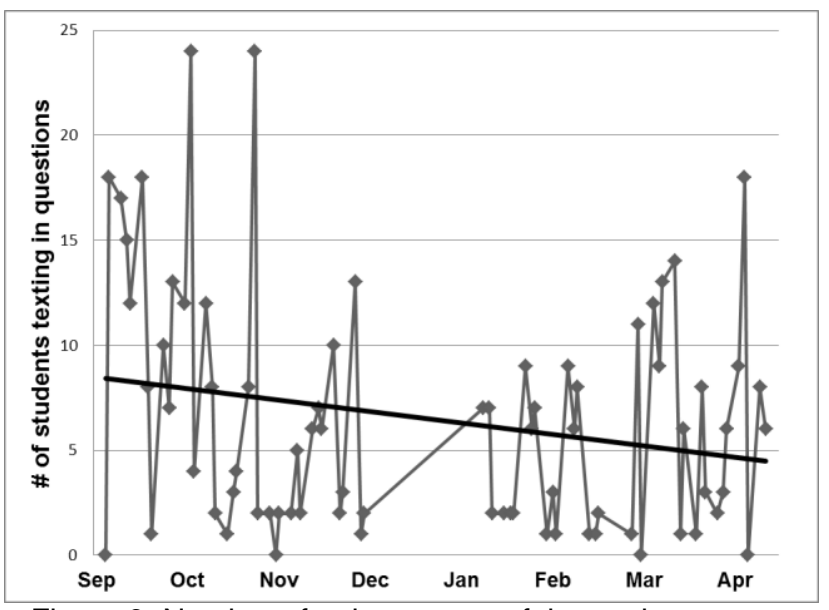

Figure 3: Number of unique users of the texting system

The y-axis in fig. 3 captures the number of unique cell phone numbers texting in questions. It does not capture the number of unique questions asked. In other words if a student asks multiple questions in a lecture they are only counted once.

The trendline in fig. 3 indicates a decrease in users of the system over the course of eight months. In the fall term (Sep to Dec) there is an average of 7.5 unique users of the system per lecture. In the spring term (Jan to Apr) there is an average of 5.4 unique users of the system per lecture. The attendance range for the fall term according to Iclicker data was 464 to 830 students, with an average of 661 students. Therefore even an average of 7.5 users per lecture represents a tiny portion of students in lecture. Though an increase in the number of users is desired, given the common wisdom that for every question asked a large number of students stay silent with the same question, this tiny portion is still acceptable.

\subsection{Instructor Opinion of SMS System}

The first instructor to make use of the texting system is convinced of the value that texting brings to the learning environment. He states, "Often large classes are more like a stage play or movie than a classroom. The ability of the 
class to interact increased the concentration level and shifted the perception of the experience on both sides."

Another instructor reports that one student reported that when the instructor announced, for the first time, that students should text in their responses to the design challenge and that they would henceforward be allowed to keep their cell phones on, "you could feel the entire balcony relax." He goes on to say that texted questions are not interruptive. They are not even as distracting as hand-raising. Receiving questions via SMS allows the instructor to answer the questions at an appropriate time, such as when she or he can actually look at them and think for a moment - for example, as students are answering an IClicker question or considering a problem in a Think-Pair-Share challenge. More than just assessing what lecture material the students are having trouble with, the texted in questions provide the instructor with a good sense of where the student's overall concerns are, since they often ask questions that have to do with material outside of the lecture at hand.

\subsection{Student Opinion on SMS System}

An online optional survey was used to collect student feedback on the course at the end of year. The survey was anonymous, however we tracked which students had completed the survey (but not their responses). This semianonymous method allowed us, as in previous years, to offer a prize for completing the survey. The survey contained one question about texting in class that read, "Texting in of questions during class was useful to me." There were 156 completed surveys out of approximately 950 students enrolled in the course; a $16.4 \%$ response rate. This was lower than in previous years, however still a significant enough absolute number of responses to allow for extrapolation.

The majority of students, $58.4 \%$, used the texting system. This was lower than expected as the intent of the question was to identify students who had texted in questions, read the posted question / answer lists, or were actively paying attention when texted questions were responded to in lecture. The numbers indicate that student only associated actual texting in of questions as "accessing this resource."

Of those that accessed the system two thirds found the system useful (31.4\% of the entire class population). About one third (16.7\% of the entire class population) did not find the system useful. Finally $9.6 \%$ of the class population had no opinion on the system's usefulness. These are summarized in fig. 4.

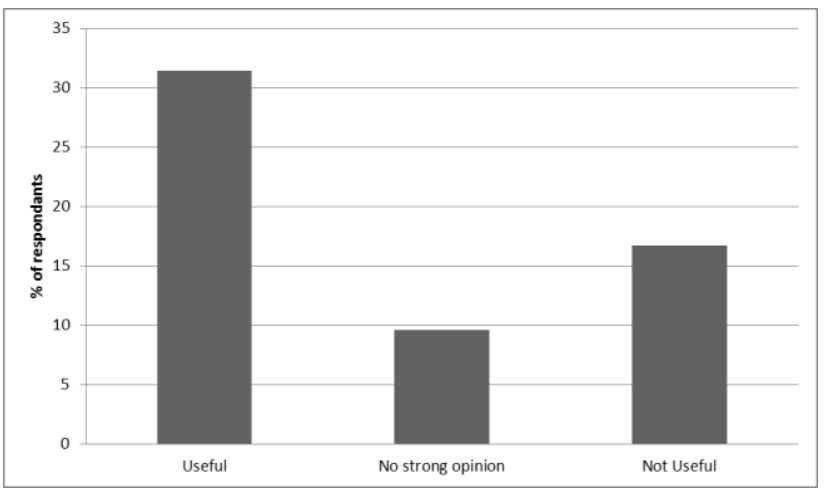

Figure 4: Student opinion of SMS system from optional year end survey

These results show that though not overwhelmingly positive, there is a large contingent of students, several hundred if the data is extrapolated to the entire course enrollment, which find value in the ability to text in questions. Of those that did not find the system valuable, its existence no more intrudes on their learning experience than the common practice of an instructor answering other student's questions in lecture.

\section{CONCLUSIONS}

After a three month pilot followed by a complete year of full implementation the verdict is that the use of SMS within the classroom is a success and will continue to be part of the course. Quantitative data shows that a small but persistent number of students were making direct use of the system by texting in questions. The assumption is that this small group is representative of a much larger group getting educational benefit from the answers provided to these questions.

Instructors are highly positive to the tool expressing appreciation for any method that allows for a better connection with their students, particularly in a large class.

Finally the texting system was perceived by about one third of student survey respondents to be a useful resource. If extrapolated to the entire course population this system is having a positive effect on hundreds of students.

Given that the resource costs to run this system were low relative to course resources, the system will continue to run next academic year albeit with some optimizations indicated in the future work section below.

\section{FUTURE WORK}

While the decision to continue with the texting system has been made, there are several areas where the process will be optimized before the next implementation. 
The course cell phone number will be better communicated to the students. A standard slide template with the course cell phone number in the footer will be made available to all five course instructors. The goal is to make this number available to students at all times.

A standard process for dealing with questions not answered within the lecture in which they were asked. Currently this varies between instructors. For example some instructors prefer to answer the questions on the course website, while others prefer saving the questions for the next lecture. A standard process will keep this resource consistent for students.

Commercial and freeware software capable of extracting text messages from the cell phone into an easily read and manipulate file format is being explored. These solutions include but are not limited to Dexrex and IPD Dump. These solutions are also being considered for inclusion in a student designed learning software systems. This software will reduce the resource cost of the system by reducing the workload on the administrative staff. It will have the additional benefit of increasing the data collection resolution from a unique user level to a unique question level.

Currently only questions that are not answered in lecture are being posted. The new lecture capture system implemented in this course is a natural remedy for this. In future implementations all questions asked will be posted. Answers that were not addressed in lecture will be included in written form as per this year. However if a question was answered in lecture then a link to the lecture capture video will in included. This will create a more complete resource for students and will hopefully increase the number of users of the system outside of lecture.

\section{Acknowledgements}

The idea for this project came from the hard work of a first-year student design team. They were the first to recommend the embracing of text messaging in the classroom as a means of increasing student interactivity. Thank you to R. Chiu, H. Shen, S.H. Lee, and S. Srinivasan for your hard work.

This system could not have been implemented and the data collected without the dedicated work of the course administrative staff P. Huynh and T. Cheng. Thank you for all your support.

\section{References}

[1] Rosemary Chiu, Hong Shen, Sung Hoon Lee, and Shruti Srinivasan. Student Feedback Mechanism in Convocation Hall at the University of Toronto. Undergraduate Design Project, Faculty of Applied Science and Engineering, University of Toronto, 2003.

[2] Ilker Yengin, Adem Karahoca, Dilek Karahoca, Hüseyin Uzunboylu, Is SMS still alive for education: Analysis of educational potentials of SMS technology?, Procedia Computer Science, Volume 3, 2011, Pages 1439-1445, ISSN 1877-0509, 10.1016/j.procs.2011.01.027.

(http://www.sciencedirect.com/science/article/pii/S1877050911 000287)

[3] C. Markett, I. Arnedillo Sánchez, S. Weber, B. Tangney, Using short message service to encourage interactivity in the classroom, Computers \&amp; Education, Volume 46, Issue 3, April 2006, Pages 280-293, ISSN 0360-1315, 10.1016/j.compedu.2005.11.014.

(http://www.sciencedirect.com/science/article/pii/S0360131505 001624) 